\title{
Graphic Novels as History: Representing and Reliving the Past
}

\section{Ben Lander \\ York University}

Chester Brown, Louis Riel: A comic-strip biography (Montreal: Drawn and Quarterly, 2001).

Marjane Satrapi, Persepolis: The story of a childhood (New York: Pantheon, 2003).

Marjane Satrapi, Persepolis: The story of a return (New York: Pantheon, 2004).

Art Spiegelman, In the Shadow of No Towers (New York: Pantheon, 2004).

When Art Spiegelman won a Pulitzer Prize for Maus: A Survivor's Tale, in 1986, sequential art in the form of comics and graphic novels began to receive interest as a serious medium for artistic expression. Since the mid-80s, comics and graphic novels have been staking a greater space within contemporary culture. With the appearance of feature films based on comic books, including American Splendor, Ghost World, and Sin City, not to mention Spiderman and the various incarnations of Batman, cinema audiences have been treated to a broad spectrum of what the medium has to offer. In their paper form, graphic novels have also been receiving critical acclaim from literary reviews and can be found in many bookstores with dedicated sections as well as most public libraries.

The discipline of History has not been completely unmoved by this broader cultural interest in sequential art. Instigated by the cultural turn in the 1980 s many scholars, with interests ranging from gender, politics, and culture have turned to comics as a primary source of information on a variety of topics. This work, much of it excellent, utilizes textual analysis to examine comics in a detailed and thorough way in search of linguistic, narrative, and artistic nuance. Yet despite this interest in comics as a primary source, there has been little interest in the possibility that comics might provide an alternative form for representing historical narratives. Joseph Witek's Comic Books as History: The Narrative Art of Jack Jackson, Art Spiegelman, and Harvey Pekar (1989) is the only monograph on the subject and appeared over a decade and a half ago.

Historians are aware, however, of the representational limitations of the

113

(C) Left History

10.2 (Fall 2005) 
text-based narrative form. Indeed, Hayden White, throughout his oeuvre, particularly Figural Realism (1999), The Content of the Form (1987), and Tropics of Discourse (1978), has been hammering the point home that the representational strategies of History remain tied to the discipline's conservative epistemological foundation. Historians, White argues, continue to write like nineteenth-century English novelists, unable or unwilling to acknowledge the inherent problematic nature of this omniscient literary style.' White makes a strong case for historians to employ alternative forms of history when they write about the past. ${ }^{2}$

In The Content of the Form White is concerned with "the relation between narrative discourse and historical representation," and particularly the problems this relationship causes "for historical theory." Historians, White argues, need to realize that,

narrative is not merely a neutral discursive form that may or may not be used to represent real events in their aspect as developmental processes but rather entails ontological and epistemic choices with distinct ideological and even specifically political implications. ${ }^{3}$

White explains that "the exclusive use of the third person" in historical narration means the story is presented as entirely objective, with the historian hidden behind an omniscient narrative, which becomes a problem when recording people and events. In these instances the narrative makes truth claims that the evidence can never fully support. ${ }^{4}$ Every historian pushes evidence in places when it does not quite fit, often laying a narrative across an omission like a board across a fissure. This is a central issue for a discipline whose epistemological claim rests on the ability to provide a true representation of the past. The problem is compounded when we realise that historians rely on particular narrative techniques when writing their purportedly true portrayals, and this is something that historians do not generally admit..$^{5}$ Instead they present the story as if it were found in the events, there to be discovered by the diligent historian, not the result of creative artifice on their part. ${ }^{6}$ This is not the case in comic histories, where the medium itself, as well as the culture of comic artists, makes the author's role in the creation of the narrative a central element of the representative process.

In "Historical Emplotment and the Problem of Truth in Historical Representation," White argues that Spiegelman's Maus "manages to raise all of the crucial issues regarding the limits of representation." He views Maus as an example of historical representation that chooses a seemingly inappropriate mode of emplotment, a satirical allegory, in an equally inappropriate form, the comic book, to represent the Holocaust. Yet, as White argues, by making the subject of the book the effort on Spiegelman's part to extract the story of his parent's experience of the Holocaust, Spiegelman frames the historical narra- 
tive within a further frame. Maus is precisely about the representational struggle of presenting even a small part of the larger history of the Holocaust. ${ }^{8}$ Comic artists use numerous techniques unique to their medium in order to shape narrative and engage the reader.

A few words need to be said about the difference between reading comics and reading text. The most important is the fact that comics are broken up into numerous independent panels that are disposed in a specific manner on the page. Indeed, the medium of comics demands that the narrative be fragmented; time, space, and meaning are always fractured in ways literary modernism could never approach. Independently, each panel's meaning is limited; however, through the deliberate and voluntary acts taken by the reader the actions, meanings, scenes, etc., represented in the panels are given significance through the act of closure. In his comic book on the history and mechanics of comics, Scott McCloud argues that closure is the act through which the reader completes the implied meaning of a panel, an act that "allows us to connect those moments and mentally construct a continuous, unified reality." Closure is one of the ways reading a comic or graphic novel is different from reading text.

In fact closure is not restricted to comics - it is just more prevalent in this medium than elsewhere. We use closure everyday to make sense of photographs, illustrations, moving images, and even text. A vivid example is the famous photograph of the South Vietnamese police chief executing a suspected Vietcong in a street full of journalists. The photograph shows us the moment immediately preceding death. Robert Capa captured an eerily similar moment in a photograph of a soldier being shot during the Spanish Civil War. In order to understand these photographs we have to complete the implied action; i.e. we have to complete the death of these individuals being photographed in order to understand the images. The intense experience that closure involves the reader in is one which comics depend on over and over again, in two different ways: within each frame and between each panel.

In the first form of closure, the same as in photographs, the reader is required to interpret and understand the represented image. For example, when Marjane Satrapi draws herself walking through the streets of Tehran, what actually appears on the page is a black figure standing in the air with one foot in front of the other. It is up to the reader to take that motionless blob of ink, make it into a person, and move it through the city. If the reader chooses not to perform these tasks the comic would be rendered meaningless. Comic artists have developed several means to aid this process. Beyond the positioning of the human body into recognizable positions, artists add motion lines and shading to indicate movement, speed, and direction to assist the reader.

In a second form of closure, the reader is required to fill the gaps between each and every panel (known as "gutters" in comic parlance) in a comic strip or graphic novel. This type of closure is unique to comics. Its effect is to make 
the reader "a willing and conscious collaborator" where "closure is the agent of change, time and motion." 10 An evocative example of this can be found in Chester Brown's Louis Riel (2003). In one panel, Thomas Scott kneels on the ground waiting to be executed with only the frozen ground and a brick wall as company within the frame $(72$, panel 3$)$. The reader views the lonely scene at close range, just at the edge of the firing squad, possibly as part of that group, one which stands barely outside the view of the frame. The next panel is completely blank. In the third panel Scott lies on his side, mouth open, blood staining his shirt. He has been shot by the firing squad. In closing both gutters and the blank panel (itself functioning as an oversize gutter) the reader becomes involved in the death of Scott. Making their way through the following four panels, watching Scott moan on the ground as a man walks slowly to administer the fatal shot, the reader closes five gaps in the narrative, and, in so doing, closes out the life of Thomas Scott.

Closure is, perhaps, the single most important difference between reading history in the form of graphic novels and traditional historical writing. When reading comic histories the reader is inserted into and becomes involved in the action of past events in a way that is not required when reading a traditional historical text. The reader participates in the development of the narrative, thereby coming much closer to the creative process of representing and understanding the past. A type of closure sometimes appears in text in the form of an ellipsis at the end of a sentence where the reader closes that which is previously alluded to. While the use of this is rare in writing, the act of closure in comics is never-ending, a situation that leaves the reader closing the implied actions and meanings of all sorts of events and scenes, from the mundane to the most significant. Closure incites the reader into a more engaged experience of reading.

Alongside closure, the visual elements of comics further engross the reader. They allow the reader to linger on pages, often offering extra-narrative meanings through their use of space and the juxtaposition of graphic details. The desire to involve the reader in the narrative as an active member is critical to the experience of comics. Spiegelman recently spoke on this subject in the context of Maus. "My drawing technique was meant to have an intimacy of handwriting. I wanted a certain kind of directness and casualness. I did not want to use a technique that separated the work from the reader." These words reflect a preoccupation Spiegelman, Satrapi, and Brown share; indeed, they also speak to two important differences between a traditional written history and a comic history, those of style and interest.

I believe there is a connection between the form and the subject of traditional and comic histories that needs fleshing out. In traditional histories it is the public arena that receives the most attention, and this space is narrated from a distance which itself mimics, or is mimicked by, the largeness and perceived 
importance of the subject. Of course, the distance is itself a tool that allows the author, and reader, to view the past from a position of authority, one that is detached, often inhuman in its scope. On the other hand, comic histories tend to revel in the minute personal details of everyday life, which receive their due respect because of their personal or symbolic weight within the lives of the characters and the narrative that is being constructed. This concern with people and symbols is obvious for anyone who reads these beautifully crafted works where the hand and brush of the artist is always evident and the scenes are viewed from within the narrative. A comparison could even be made between the artisanal quality of comics and their reliance on ancient forms of storytelling and the industrial aspects of academia with its arcane rules, massive bureaucracy and with the mechanical interface of the printed word. The goal of these and other comic artists is, in part, to transcend the divide between creator and reader, a situation that leaves open numerous possibilities for understanding the past as well as its representation.

Brown's epic comic-strip biography Louis Riel was rightly celebrated as an ambitious rendering of an often-overlooked figure of dissent in the conservative field of popular Canadian history. The book is exceptional for its use of space and details to control the tone, timing, and speed of the narrative. Within the form of comics "time and space are one and the same," both dependent upon the shape and size of the panel where the scene is represented. ${ }^{12}$ Brown uses a traditional six panel per page layout, a style from which he does not divert. This uniformity provides a steady speed to the book, like a metronome or heartbeat, the perfect pace for a biographical narrative. In order to draw attention to the passage of time, Brown lingers on moments to emphasize their importance to the story of Louis Riel. These include: Riel's 1876 imprisonment in the insane asylum L'Hospice St. Jean de Dieu near Montreal; the events leading up to and including the execution of Thomas Scott on 4 March 1870; and most dramatically, Riel's trial in Regina in July 1885 where the events appear on 29 consecutive panels where the usual white background has become black and the figures appear as ghosts against the oppressive gloom. Brown uses this technique at select moments in the book to dramatise significant moments.

Brown controls the tone of the book in a similarly sparse manner. Visual details are kept to a minimum, thus avoiding symbolic clutter that could deflect from the narrative. This is not to suggest that Louis Riel is simply illustrated, but that details are reserved to emphasize the tone of panels; they also mimic the flatness of the prairie landscape where the events took place. The amount of black or white that appears as the background in each panel is the primary indicator of tone; however, the degree of sharp angles and curved lines, and detail of surroundings, also shape the mood in which each panel and page is presented. Brown tends to use the background to emphasize the dialogue or action, where both sparse or empty space and dramatic cross-hatching are used. 

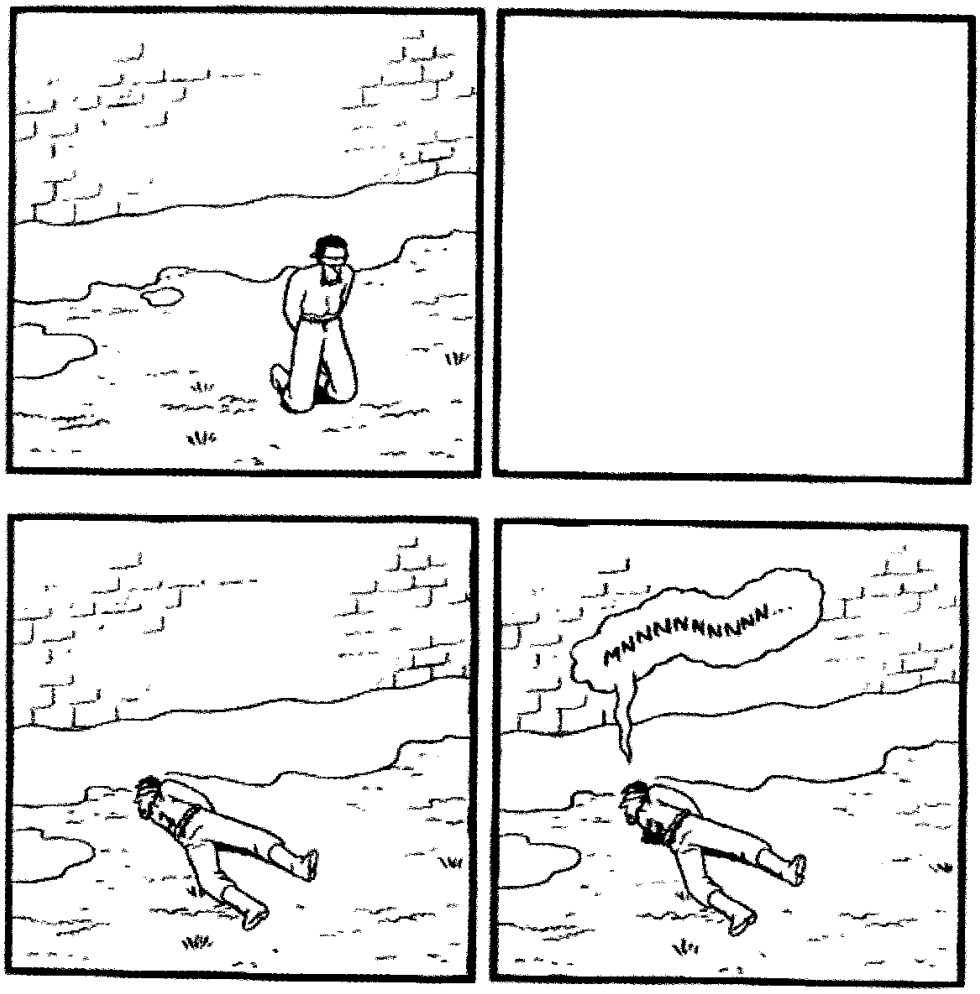

Thomas Scott's death in Chester Brown, Louis Riel: A comic-strip biography (Montreal: Drawn and Quarterly, 2001), 72, panels 3-6.
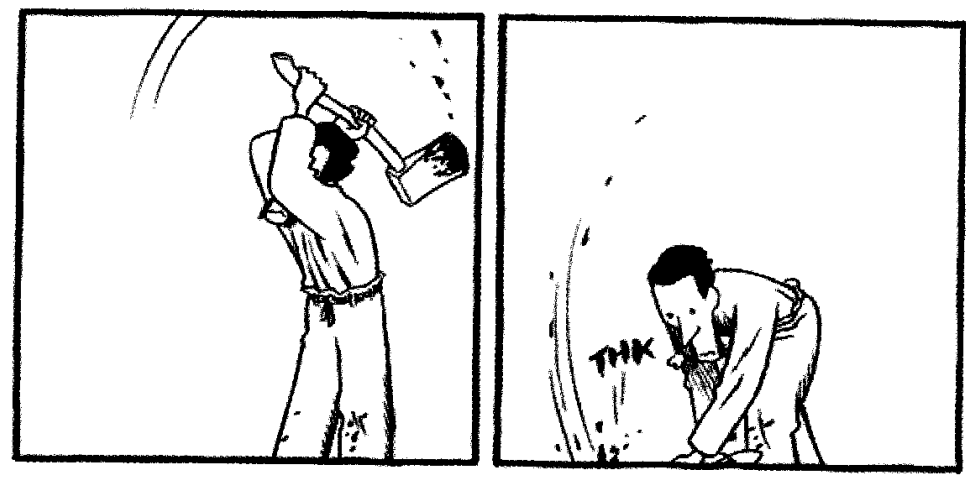

The killing of Norbert Parisien by Thomas Scott in Chester Brown, Louis Riel: A comic-strip biography (Montreal: Drawn and Quarterly, 2001), 55, panels 1-2. 
Brown notes that this style was a result of his love of Hergé's Tintin, but more directly influenced by Harold Gray's Little Orphan Annie. The influence of historical comics on present comic artists is common and connects Brown to Spiegelman who mobilizes that history in new and radical ways.

The rigid structure of Louis Riel means that the almost essential authorial commentary is reserved for the notes section at the end of the book (this style of commentary, along with deprecating self-depictions, is a major part of North American comic culture; it is a different form of the self-awareness and indulgence played out in the mix of sex, violence, and awkwardness that characterize the 1960s comix). In this section, alongside the bibliography, we learn much about the construction and methodology of Brown's work. First of all, Brown relies on secondary sources for his information, and builds his narrative by evaluating different versions of the same event and shaping them according to his own vision of how history should be told. It turns out to be one where the hand of the creator is just as strong as that of an academic but unlike the latter, in comics the creator usually reveals his role in the construction of the narrative. The notes themselves are of importance in understanding the relation between comic histories and academic histories. Whereas notes in an academic history are meant almost solely to bolster the truth claims of the narrative, Brown uses his notes to point out the numerous gaps and authorial intrusions in his narrative. These include places where he fudged the information in the historical record to make it conform to his narrative and to the visual nature of his particular comic form. For instance, Thomas Scott is drawn as the sole and merciless killer of Norbert Parisien. Brown admits in the notes that "it's likely that the murder was more of a group effort" yet drew it as he did because the single figure wielding an axe was more dramatic (248). Notably, this representational decision places the reader in the position of Scott, closure coming to the sickening sound of metal on flesh "thk" (55, panel 2). One reason this works in comics is that its form is amenable to the use of symbols, thus Scott appears on the page both as himself and as a symbol of the violence, racism, and rough masculinity that characterized Western Canada at the time.

Historical fiction and historical cinema reshape the historical record in similar and equally effective ways. In a review of the film The Gangs of New York, a film which in truth I disliked, Bryan Palmer argues that the combination of a "conceptual imagination with a rigorous and disciplined recourse to actualities of evidence and event, thrives first and foremost through its creative licence." That creative licence succeeds, Palmer argues,

if it historicises experience in ways that illuminate truths that are often obscured over time, and that have remained hidden from engagement precisely because large connections and continuities in historical process have been seemingly fractured by change, the tyranny of present-mindedness (which 
severs our lives from those of earlier generations), and the necessary but unfortunate limitations of painstaking scholarly reconstructions that often get the empirical detail of various trees right only to lose sight of the broad expanse of the forests of the longue durée. ${ }^{13}$

Brown succeeds, I believe, in using his pen and brush to create a narrative that speaks to the social and political climate of the present. The theme of the book, the conflict between an individual forced to organize and defend a way of life against the combined threat of the state and capital, symbolized by Prime Minister John A. Macdonald and George Stephen, the president of the Canadian Pacific Railway, draws numerous comparisons with events around the world and in Canada. Brown's treatment of Riel's visions appear comprehensible, not mad, in accord with present views of mental disorder.

Other instances of the hand of the artist show humility to acknowledge one's mistakes while remaining true to the goal of the project. Brown admits he represented a person or object differently than is described in secondary sources because he forgot to look at his notes, or discovered the information once the panels had already been drawn. On this point Brown notes that he considered redrawing the panels, "but then decided that I could live with that level of inaccuracy" (246). After all, drawing comics is time intensive and by working with the details Brown was able to create a stronger story. Such admissions speak directly to White's contention that the author of history removes himself from the narrative by pretending that the emplotment was found in the facts themselves. Brown never hides from the fact that Louis Riel is his creation, built according to his understanding of the events that he deduced. Of course Brown is not a historian but an artist and can therefore "get away" with these creative decisions in a way that would not be acceptable in the work of an academic historian. Although I am not necessarily advocating making similar decisions, I do find his candour admirable. By providing these notes, Brown allows the reader to walk away from Louis Riel having read and experienced a fascinating story based extensively on historical record, while being engaged by universal themes of power and resistance that Brown made central to his narrative of Riel's life.

A similar honesty pervades the first two volumes of Marjane Satrapi's Persepolis $(2003,2004)$ as their foundation in memory leads to narratives that juxtapose public and private events. The books narrate Satrapi's life story alongside the history of Iran, in particular the effects of the Islamic Revolution. Their basis as works of memory is reflected in the layout and style of both books. Satrapi shapes her panels according to their importance in her memory; moments of private trauma and thought fill much of the book. This, of course, is a unique representational tool for comic artists, and is used in various ways to structure the speed, tone, meaning, and importance of particular narrative 

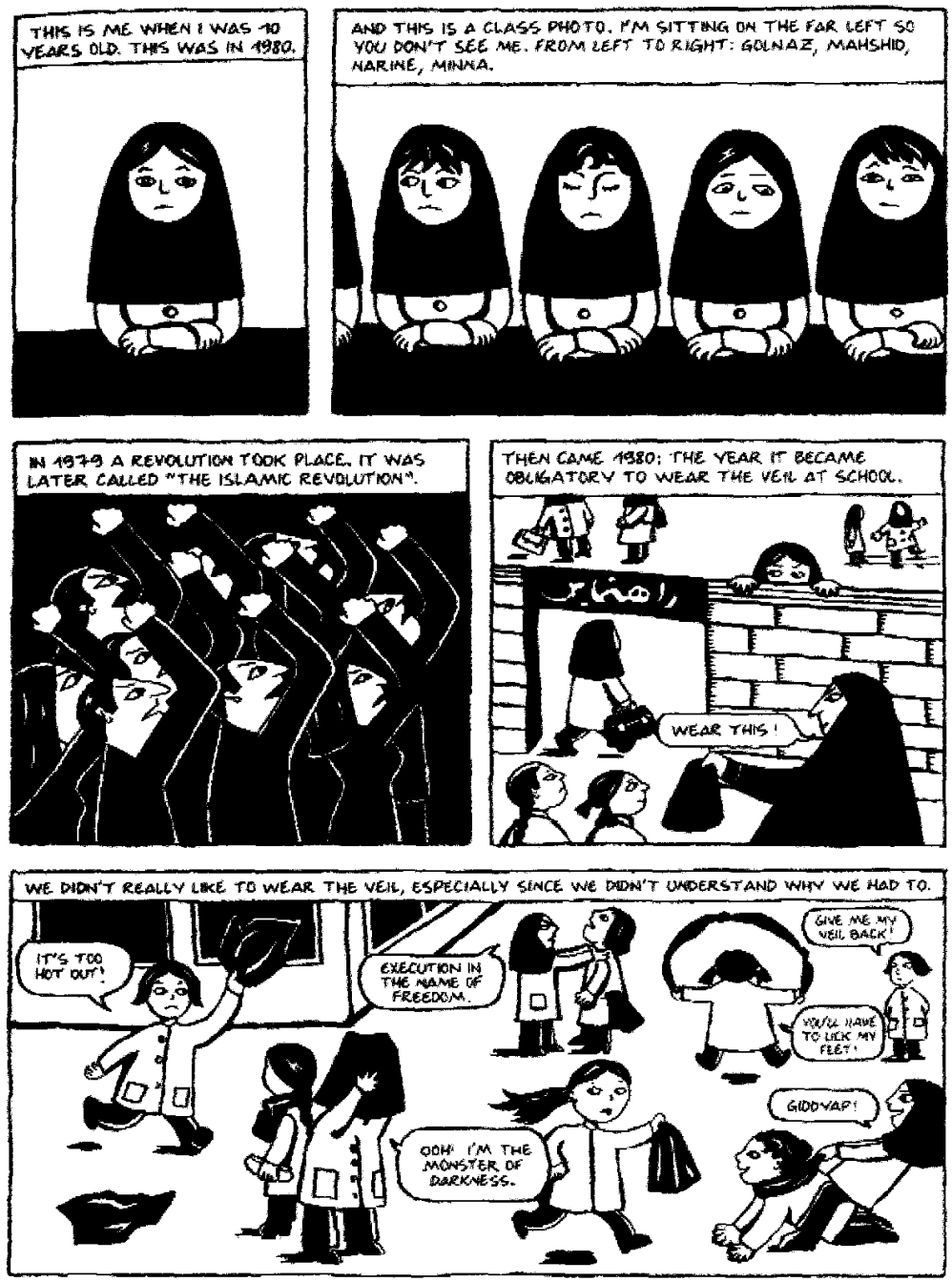

Panels from "The Veil" in Marjane Satrapi, Persepolis: The story of a childhood (New York: Pantheon, 2003), 3, panels 1-5. 
events. As we saw with Brown, the use of space by comic artists can offer much to the narrative. Satrapi often extends a panel horizontally where it then takes the space of two panels, or extends along a whole row. This technique, along with other types of page breakdowns and full-page panels, are well used to convey the complexity and relative importance of different moments in Satrapi's life. One of her most successful representational strategies is the depiction of scenes from her position within the narrative, i.e. we see scenes as she saw them, scenes that look like photographs on the page, and indeed tend to be moments when photographs were surely taken, such as her wedding (161, panel 4). Satrapi also uses more common pictorial strategies such as the comparison frames (this not that) found in instructional literature.

Being a medium that is so suitable to dealing with symbols, it is appropriate that this graphic novel begins with a chapter on the veil. The headscarf makes appearances throughout the books where it is at the centre of Satrapi's relationship as a woman - an educated and rebellious one - with her society in general and the guardians of the Islamic revolution in particular. In the first chapter Satrapi explains that at the age of 10 when the revolution took place she attended a French non-religious school where the veil received various amusing responses from children reacting to rules they did not understand. In a large panel covering half a page children play at school; one little girl shouts out "Execution in the name of freedom" in a game with a friend, while another has found or taken 4 veils and tied them together to form a skipping rope which she uses as another girl looks on: Is she waiting for her turn? Hoping for her veil back? Or just bemused as the reader no doubt is $(2003,3$, panel 5)? Humour is a foil Satrapi uses to represent the imposition and effect of state regulations on her life, her family, friends, and society. Dark humour and irony are recurring devices in comics to used to critique anything that rings of official doctrine. As Brown's use of notes shows the presence of the author's hand in the editing of the narrative, Satrapi uses her own techniques to intrude on representations of the past.

Alongside the veil, other aspects of fashion and the body are a central motif in the first two of Satrapi's books. In Persepolis: The story of a childhood, Satrapi relays her exuberance of receiving a jean jacket from her parents, along with punk music and posters, on their return from Turkey. Fashion and music become a site of private rebellion against the restrictive regulations in Iran. In the second book details of puberty and experimentation with hair and clothing styles while at school appear alongside trials of life in Austria as a young Iranian woman. Satrapi uses the form of comics to accentuate moments of anxiety or joy. By alternating the number of panels where she appears alone or with others, the reader is able to view her loneliness, her internal thoughts, and her relationships with individuals and groups. These stories are told alongside more public events including the Iran-Iraq war and Republican crackdowns on 
political dissidents; yet these also appear through the lens of Satrapi's experience.

The relationship between personal and public trauma is at the centre of Art Spiegelman's new book In the Shadow of No Towers (2005). Spiegelman defines the space of the work as "that faultline where World History and Personal history collide" (1). In trying to make sense of the chaos surrounding the events of $9 / 11$, from the panic in the streets to the US government's jingoistic response, Spiegelman turns to "the collage-like nature of the newspaper page ... to juxtapose [his] fragmentary thoughts in different styles" (2). He uses over a dozen styles of illustration, each specifically chosen to reflect not only the tone but also the type of artwork suited to represent different memories, scenes, and thoughts. The styles are raised from all ages of comic illustration, an idea Spiegelman hits upon after turning to early twentieth-century comics for solace. By connecting the aftermath of $9 / 11$ to the history of comics, Spiegelman develops a layer of meaning based upon issues of terrorism, race, and disorder that historic comic artists drew upon to comment on American society and which, as Spiegelman demonstrates, continue to haunt the psyche of Americans. Spiegelman presses this argument, and an accompanying comment on progress and history, through the reproduction of newspapers from exactly a hundred years earlier when America was in a similar state of furious excitement over the shooting of President McKinley. In reproducing primary sources and incorporating their figures and ideas into his comics, Spiegelman forces the reader to consider the relationship between the past and the present in a direct and visual manner.

Spiegelman uses the form and space of the comic page as a driving force in his narrative. This is explicit on numerous pages when vertical columns are employed to mimic the standing or falling towers of the World Trade Centre. On other pages, the reader follows the glowing image of the tower as it tumbles to the ground; images of Spiegelman's tumbling body mimic the path numerous unfortunate people took to their deaths. This example forces a similar type of closure to that which Brown utilizes in Louis Riel to allow the reader to consider Scott's death as a subject of history. On a further page, the two towers stand as dark shadows covering the page. The outline of each tower encompasses a comic strip that is drawn within the boundaries of their shadowed bodies. Spiegelman uses the space to add an extra narrative dimension to the page. The element is a plane, like the one the hijackers crashed into the towers, which appears in the blank space that separates the two towers on the page. It is not part of the personal narrative on the page, an anecdote about the limits of freedom in post-9/11 America. At the point in the story where Spiegelman describes New Yorkers' paranoia, a clock/time bomb that he is holding explodes. If the reader glances to the left to see the plane, the extra-narrative element I mentioned earlier, they will see that its trajectory leads into the explo- 


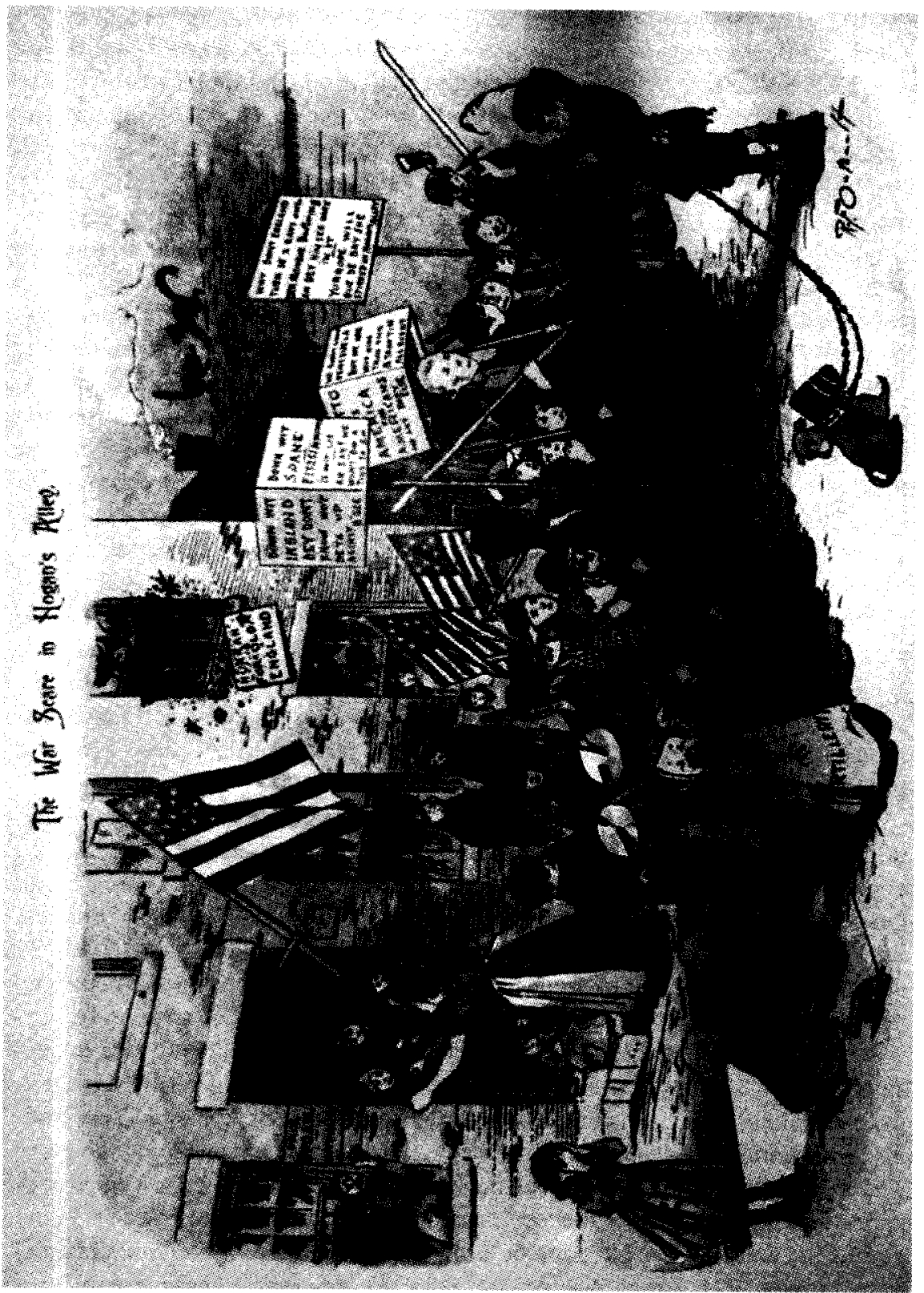

Richard Outcault, "The War Scare in Hogan's Alley," New York World, 15 March 1896, reproduced in Art Spiegelman, In the Shadow of No Towers (New York: Pantheon, 2004), plate 2. 
sion panel where all that appears is a jagged red panel with the word "BOOM!" The plane that hit the WTC has interrupted Spiegelman's personal story. In this brilliant use of form, Spiegelman draws together all the main themes of his book: the attack on the WTC, the impact of public events on private life, and in the panel after the explosion, where the author appears transformed into the cartoon character Happy Hooligan, Spiegelman brings us back to his contention that America's problems are ones that have been around for a long, long time.

The comic histories written by Chester Brown, Marjane Satrapi, and Art Spiegelman are provocative examples of how the past can be represented in an alternative and, ultimately, more engaging form. The form of comic art and the culture and history of the comic community have led comics to experiment with many techniques that rupture the divide between the creator and writer that is built into the omniscient narrative of traditional history. By challenging the authority of the omnipotent third-person in text histories, the narratives of comic and graphic novels invite the reader to see the difficulties, as well as the process, of representing the past. The self-questioning tone of comic narratives moves the reader beyond the imperative of truth and towards a more realistic position where truth, the past, and historical representation can be presented as the questions to be considered. Finally, through engagement with images and symbols, the comic artist depends on the reader to perform closure; in doing so she/he becomes an active accomplice in the historical events as well as in the difficult decisions that have to be taken when representing them.

\section{Notes}

${ }^{1}$ Hayden White, "The Burden of History," in Tropics of Discourse: Essays in Cultural Criticism (Baltimore/London: The Johns Hopkins University Press, 1978), 27-50.

${ }^{2}$ See the forum on "Writing History" in Left History 10, 1 (2004): 8-53 where David Leeson takes up White's challenge to experiment with a modernist literary technique: "Cutting Through History: Hayden White, William S. Burroughs, and Surrealistic Battle Narratives," 13-43.

${ }^{3}$ Hayden White, The Content of the Form: Narrative Discourse and Historical Representation (Baltimore: Johns Hopkins University Press, 1987), ix.

${ }^{4}$ Ibid., 3.

${ }^{5}$ White analyses several nineteenth-century historians and the narrative techniques they employ in Metahistory: The Historical Imagination in Nineteenth-Century Europe (Baltimore/London: The Johns Hopkins University Press, 1973).

${ }^{6}$ White, The Content of the Form, 21.

${ }^{7}$ White, "Historical Emplotment and the Problem of Truth in Historical Representation," in Figural Realism: Studies in the Mimesis Effect (Baltimore/London: The Johns Hopkins University Press, 1999), 31-2. 
${ }^{8}$ Ibid., 31.

${ }^{9}$ Scott McCloud, Understanding Comics: The Invisible Art (New York: Paradox Press, $2000), 67$.

${ }^{10}$ Ibid., 65.

11 "Art Spiegelman in conversation with Seth," 25th Annual International Festival of Authors, Toronto, Canada, 22 October 2004.

${ }^{12} \mathrm{McCloud}$, Understanding Comics, 100.

${ }^{13}$ Bryan D. Palmer, "The Hands That Built America: A Class-Politics Appreciation of Martin Scorsese's The Gangs of New York," Historical Materialism 11, 4 (2003): 31745,320 . 